\title{
Uncertainties in the Mercury Mass Balance in a Coal-Based IGCC Power Plant (Puertollano, Spain)
}

\author{
José María Esbrí, Alba Martinez-Coronado, Sofía Rivera Jurado, Eva García-Noguero and \\ Pablo Higueras
}

Instituto de Geología Aplicada (UCLM), Pl. Manuel Meca, 1, Ciudad Real, 13400, Spain

*Corresponding Author: José María Esbrí. Email: josemaria.esbri@uclm.es

Received: 13 January 2020 Accepted: 11 March 2021

\begin{abstract}
Mercury $(\mathrm{Hg})$ is a global pollutant that is subject to strict regulations to reduce anthropogenic emissions. The production of energy represents an important activity that leads to $\mathrm{Hg}$ emissions into the atmosphere. Of all the systems used, IGCC plants are the most promising for reducing Hg emissions, since it is possible to remove $\mathrm{Hg}$ from syngas prior to combustion. The aim of the present work was to evaluate the presence of $\mathrm{Hg}$ in the main streams of an experimental IGCC plant (ELCOGAS, Puertollano) in order to quantify Hg emissions and investigate the possibility of reducing them. The main streams of the system were sampled for three consecutive days and both the solids, i.e., raw material (coal and petroleum coke), fine and coarse slags, fly ash, sulphur, and the liquids, i.e., slag system, Venturi scrubber and saturator, were studied. The results show that an average of $12.9 \%$ of the Hg that enters the IGCC power plant is eliminated with solid waste and only $0.08 \%$ with liquid waste. There is still an average of $87.12 \%$ of $\mathrm{Hg}$ that is not accounted for in the mass balance and that could remain in the system and/or be eliminated in the streams that were not analysed. Although it is impossible to offer an explanation for the final fate of the $\mathrm{Hg}$ lost in the system based on the obtained results, the data suggest that sulphur byproducts could be primarily responsible for the elimination of $\mathrm{Hg}$ from the syngas, and that a major proportion of $\mathrm{Hg}$ should be emitted via the chimney after the syngas combustion process.
\end{abstract}

\section{KEYWORDS}

Mercury; IGCC; power plant; mass-balance; hypercinnabar

\section{Introduction}

Mercury $(\mathrm{Hg})$ poses a serious threat to the environment due to the ease with which it is emitted as gaseous elemental mercury (GEM) and its persistence in the atmosphere, which allows it to be transported over large distances to pristine areas and pollute trophic chains, especially in the oceans. The source of these $\mathrm{Hg}$ pools worldwide has been changing from natural sources (mainly volcanoes) to anthropogenic sources in the past century. Combustion processes, along with small-scale artisanal gold mining, are the main industrial activities associated with increased $\mathrm{Hg}$ emissions [1], especially fuel combustion processes used for power generation. The latter could be more important in terms of impact on the environment because there is a possibility that it could reach up to $40 \%$ of gaseous oxidized mercury (GOM) in the total $\mathrm{Hg}$ emitted by the chimney [2]. However, this statement is somewhat 
controversial. The results from most recent emission models suggest that the proportions of GOM could be overestimated, either due to an overestimation of emitted GOM or of in-plume GEM oxidation [3,4]. This uncertainty about the proportion of $\mathrm{Hg}$ species is a common factor in relation to the emissions of these industrial plants, because it is very difficult to monitor the species emitted by the chimney in order to verify the magnitude or evaluate the importance of the processes that are believed to occur once the $\mathrm{Hg}$ is emitted by the thermal power plant. The main reason for this is the high flow of emitted gases, which compromises the measurements due to the detection limits, as the levels are beyond the sensitivity of the analytical method [5].

Integrated gasification combined cycle (IGCC) power plants are obtained by adapting traditional energy production plants to convert them into a more environmentally friendly technology to produce electric power from coal. In these facilities, $\mathrm{Hg}$ enters the system as impurities in the raw material, particularly in coal, and it mainly leaves the facility as GEM due to the high process temperatures. The reason for this is the gasification process, which includes prior thermal decomposition/pyrolysis of the raw material followed by thermal cracking of the volatiles and, finally, char gasification [6]. The Boudouard reaction [7] with the steamchar reaction produces both $\mathrm{H}_{2}$ and $\mathrm{CO}$, which are the main components of syngas. This raw syngas is obtained at a temperature of $1480^{\circ} \mathrm{C}$ and needs to be cleaned up prior to use, because a wide variety of pollutants remain in the gas, mainly $\mathrm{COS}, \mathrm{H}_{2} \mathrm{~S}, \mathrm{SO}_{2}, \mathrm{NH}_{3}, \mathrm{HCN}, \mathrm{Hg}, \mathrm{P}$, and other potentially toxic elements such as $\mathrm{As}, \mathrm{Se}, \mathrm{Cd}$, and $\mathrm{Sb}$. Consequently, it is necessary to cool the syngas to remove $\mathrm{Hg}$ because this process must be performed at $30-38^{\circ} \mathrm{C}$. The most widely used process to remove $\mathrm{Hg}$ involves the use of activated carbon beds [8]. Another important step is the removal of $\mathrm{COS}$ and $\mathrm{H}_{2} \mathrm{~S}$ at $200^{\circ} \mathrm{C}$, with the elemental $\mathrm{S}$ recovered in the three-stage Claus process. A significant amount of $\mathrm{SO}_{2}$ is required to recover the $\mathrm{S}$ from $\mathrm{H}_{2} \mathrm{~S}$ and thus the process includes heating to around $1427^{\circ} \mathrm{C}$ to provide sufficient $\mathrm{SO}_{2}$ to react with the remaining $\mathrm{H}_{2} \mathrm{~S}$. This gas emits heat and generates steam in the waste heat boiler until the temperature decreases to the saturation temperature of sulphur, at which point the sulphur vapour finally condenses to the liquid phase in the condenser. The liquid sulphur is recovered after catalytic conversion and, in most cases, it is processed as elemental sulphur or sulphuric acid to be sold as a by-product [6].

ELCOGAS was an experimental facility located in Puertollano (Ciudad Real province, South-Central Spain) and it was active between 1996 and 2016. This facility was ranked second among global commercially operating IGCC plants using solid fuel in a pressurized entrained-flow gasifier. It consisted of three units: a gasification unit to generate the syngas, a combined cycle to produce electricity, and an air separation unit to produce $\mathrm{N}_{2}$ and $\mathrm{O}_{2}$ for the gasification process. The gasification facility comprised a gasification unit, an air separation unit, and the combined cycle. The fuel consisted of a 50:50 mixture by weight of local bituminous coal (41\% ash) and petroleum coke (5.5\% sulphur). The preparation of raw material included the mixing of some 2566 tonnes per day of coal with limestone in order to reduce the slag melting point, and a grinding and drying process in two parallel coal preparation trains. The fuel to produce this heat was a mixture of natural gas and clean syngas. The result of this preparation was a fuel with a grainsize of less than $90 \mu \mathrm{m}$ and residual moisture level below $2 \%[9,10]$.

The $\mathrm{CO}_{2}$ capture efficiency of the methodology proved to be very high. It is well known that IGCC technology leads to lower emissions of $\mathrm{Hg}$ in the stack than other technologies and, in the case of the ELCOGAS IGCC, $\mathrm{Hg}$ emissions in the stack were less than $4 \mathrm{~g} \mathrm{day}^{-1}$ despite the presence of around $200 \mathrm{~g} \mathrm{day}^{-1}$ in the fuel. The reduction of $\mathrm{Hg}$ emissions represents a significant challenge to adapt coaluse technologies to meet the $\mathrm{Hg}$ emissions regulations of the Minamata Convention [11].

Since the IGCC plant in Puertollano was not equipped with a specific system for removing $\mathrm{Hg}$ from the fuel generated in gasification, it was necessary to determine accurately the Hg routes in IGCC technology and to identify where the $\mathrm{Hg}$ was captured or retained before being incorporated into the fuel or being emitted via the chimney. In order to achieve this objective, a Hg mass balance for the ELCOGAS IGCC power plant was obtained by selecting streams that were a priori the most favourable to capture $\mathrm{Hg}$, including total $\mathrm{Hg}$ data for raw materials, and the main solid and liquid streams (see Fig. 1 for plant details). 


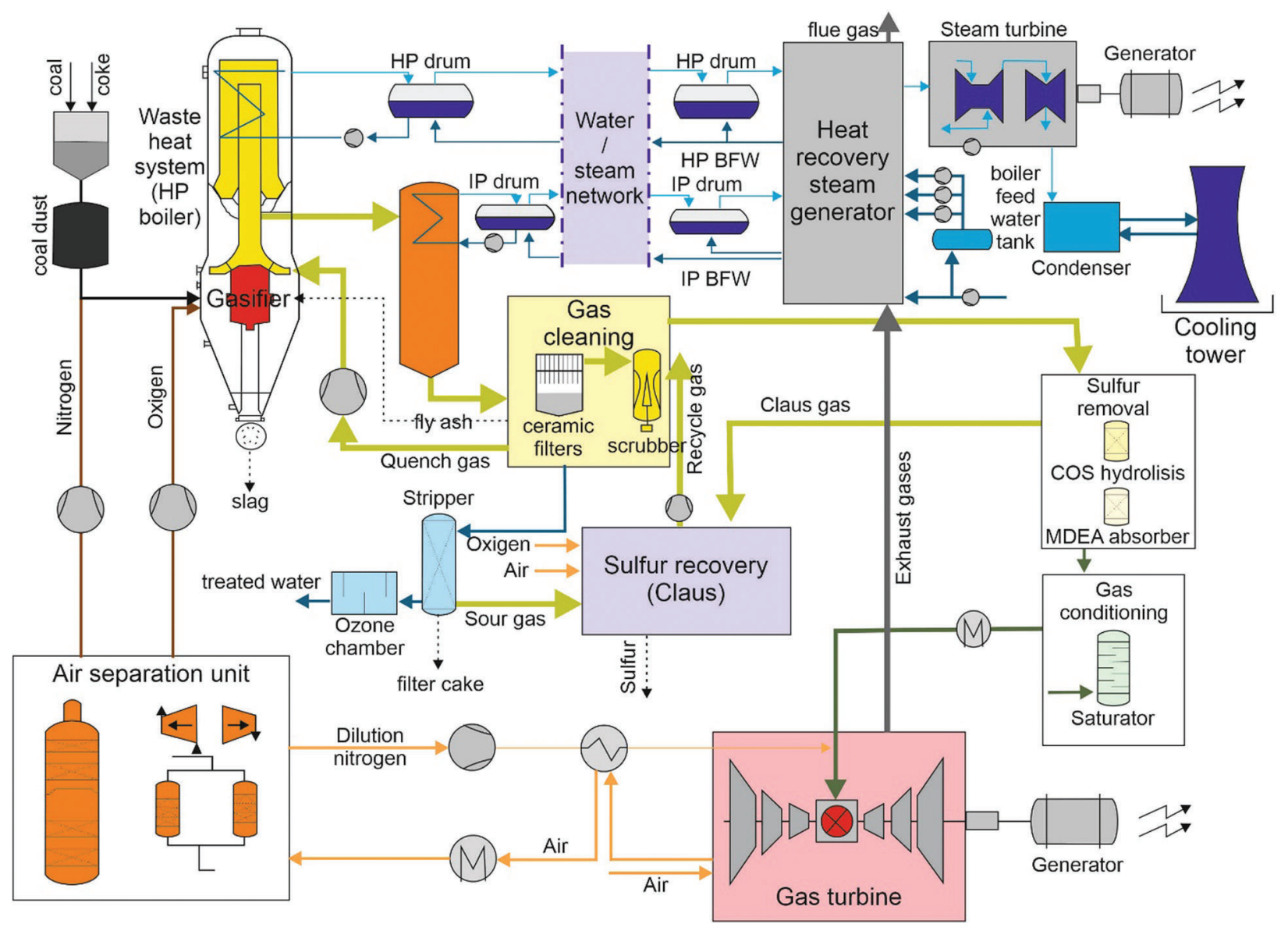

Figure 1: Simplified flow diagram for the ELCOGAS IGCC plant [12]

\section{Methodology}

The sampling design considered the expected $\mathrm{Hg}$ cycle at the facility based on the experience of ELCOGAS staff. There are numerous streams to monitor in a process as complex as that of an IGCC plant; for this reason, an attempt was made to simplify the mass balance by reducing the sampling to the following key points (see Fig. 1 for more details):

- Raw materials (bituminous coal, petroleum coke and fuel mixture)

- Solid by-products (fly ash, coarse and fine slags and sulphur)

- Liquid streams (Venturi scrubber, Slag system and Saturator)

- Claus unit reagent ( $N$-methyldiethanolamine-MDEA)

Solid samples (including raw materials and solid by-products) were air-dried for 30 days, disaggregated, and an aliquot of each was ground in an automatic agate mortar (Restch, model RM200) for five minutes prior to a homogenization stage. Sampling protocols commonly used by IGCC Plant staff were applied. Slight changes in the sampled currents are expected, so an attempt was made to evaluate their representativeness by successive sampling over three days at the selected points, from $9^{\text {th }}$ to $11^{\text {th }}$ July 2014. Liquid samples were kept in a refrigerator below $4^{\circ} \mathrm{C}$ prior to analysis.

Total Hg determinations on solid samples were carried out on a Zeeman Effect Atomic Absorption Spectrometer using a Lumex RA-915M device with an RP-91C pyrolysis unit [13]. The analysis of solid 
samples on this device included the atomization of the $\mathrm{Hg}$ content by pyrolysis at $800^{\circ} \mathrm{C}$ in a two-step pyrolyzer. The produced GEM was subsequently entrained by a stream of carrier gas (ambient filtered air) to the analytical chamber in order to quantify the $\mathrm{Hg}$ concentration. The equipment was fully calibrated prior to each analysis session and the calibration was verified every 20 determinations or each hour, at least, to avoid undesirable effects that the lamp may have on $\mathrm{Hg}$ results. Quality controls included the analysis of duplicate samples and CRMs, specifically NIST 2710a $\left(9,880 \mathrm{ng} \mathrm{Hg} \mathrm{g}^{-1}\right)$ and NIST 2711 $\left(32,600 \mathrm{ng} \mathrm{Hg} \mathrm{g}^{-1}\right)$ for low and high $\mathrm{Hg}$ contents, respectively. Recuperation rates were in the range 94.4-103.7 for NIST 2710a and 101-102 for NIST 2711.

Qualitative identification of the $\mathrm{Hg}$ compounds in samples was performed by thermal speciation [14]. Speciation data were obtained using the Lumex RA-915M Atomic Absorption Spectrometer with a PYRO915 pyrolysis attachment. The temperature increase was $0.74^{\circ} \mathrm{C} \mathrm{s}^{-1}$ during $840 \mathrm{~s}$ at $3 \mathrm{~L} \mathrm{~min}^{-1}$. The pure compounds $\left(\mathrm{Hg}^{0}\right.$, cinnabar, metacinnabar and schuetteite) used as references were produced at the IGeA laboratories by dilution with milled sand, while a soil with $\mathrm{Hg}$ bound to humic acids was used as a reference thermal desorption compound due to its similarity to the obtained sulphur thermal desorption temperatures.

Liquid samples were analysed by two techniques: 1) saturator samples by Cold Vapour Atomic Fluorescence Spectrometry on a Millenium Merlin device according to US EPA procedures [15]; 2) Venturi, slag and MDEA samples by Atomic Absorption Spectrometry on an AMA254 system. Saturator samples were pre-treated with $\mathrm{KBr}$ and $\mathrm{KBrO}_{3}$ mixed in aqueous $\mathrm{HCl}$ to convert all $\mathrm{Hg}$ species present in the liquid sample into $\mathrm{Hg}^{2+}$. Cold vapour generation requires the use of a reducing agent, which in this case was $\mathrm{SnCl}_{2}$ in $\mathrm{HCl}$. The theoretical detection limit of the equipment was $0.1 \mathrm{ng} \mathrm{L}^{-1}$ under the used analytical conditions. A full calibration was performed prior to each analysis session using a Scharlau ICP Standard $\mathrm{Hg}$ Solution $\left(1.000 \pm 0.002 \mathrm{~g} \mathrm{Hg} \mathrm{L}^{-1}\right.$ in $\mathrm{HNO}_{3}$ at $\left.2 \%-5 \%\right)$ as standard. Quality controls included the analysis of an CRM Panreac AA Standard Hg Solution $\left(1.000 \pm 0.002 \mathrm{~g} \mathrm{Hg} \mathrm{L}^{-1}\right.$ in $1 \mathrm{~N}$ $\mathrm{HNO}_{3}$ ). Recovery rates were 97\%. Venturi, slag and MDEA samples were decomposed in a front-end combustion tube at $750^{\circ} \mathrm{C}$, concentrated in a gold trap and quantified using $\mathrm{O}_{2}$ as the carrier gas and heating the amalgamator at $900^{\circ} \mathrm{C}$. The spectrometer was fitted with an element-specific lamp that emitted light at a wavelength of $253.7 \mathrm{~nm}$ and a silicon UV diode detector for $\mathrm{Hg}$ quantitation. A CRM was used to ensure QA/QC and recovery rates of 94.2-101.3 were determined for NIST 2710a.

Gaseous elemental mercury (GEM) in the atmosphere of the surroundings of the IGCC plant was measured by means of a fully portable Atomic Absorption Spectrometer (Lumex RA-915M). This portable equipment is one of the most appropriate to make environmental monitoring around a known emissions source [16]. Measurements were performed over a brief period (maximum two hours) during the middle hours of the day to ensure maximum micrometeorological stability. The method included the acquisition of one GEM data point each second and the points were georeferenced using GPS technology. Measurement criteria included measurements close to the main suspected $\mathrm{Hg}$ sources of the Ojailén valley and measurements at increasing distances from these sources until background values were reached. The main details of this monitoring mode can be found in reference [16].

\section{Results and Discussion}

\subsection{Solid Streams: Wastes and by-Products}

The raw materials for IGCC fuel showed significant variations in $\mathrm{Hg}$ contents, namely $240-446 \mathrm{ng} \mathrm{g}^{-1}$ in the bituminous coal and 36-91 $\mathrm{ng} \mathrm{g}^{-1}$ for petroleum coke. These data were consistent but slightly lower than previous data for Puertollano coals (400-571 $\mathrm{ng} \mathrm{g}^{-1}$ ) [17] but they were markedly higher than the average $\mathrm{Hg}$ contents in international coals (30-190 $\mathrm{ng} \mathrm{g}^{-1}$, with an average of $\left.91 \mathrm{ng} \mathrm{g}^{-1}\right)$ [18]. Despite this fact, petroleum coke showed higher $\mathrm{Hg}$ contents but similar variability in this study (36-91 $\mathrm{ng} \mathrm{g}^{-1}$ ) when compared to previous data from 2010 (6.9-42 $\mathrm{ng} \mathrm{g}^{-1}$ ) [17]. The sources of $\mathrm{Hg}$ in petroleum coke are directly related to variability in petroleum providers, with Asiatic crude oils generally more Hg-enriched than those from the rest of the World [19], i.e., $220 \mathrm{ng} \mathrm{g}^{-1}$ vs. $2.5 \mathrm{ng} \mathrm{g}^{-1}$ for the other continents on average. It is also 
worth noting that in the Puertollano refinery, crude oil from Croatian deposits was treated with special care due to the high content of $\mathrm{Hg}$ and sulphides, which increase the corrosion capacity on pipes [20]. The compositional variability in crude oils is very high and problems related with the presence of trace elements are complex, thus explaining the variability in petroleum coke used at the ELCOGAS facility. Fuel mixture values were, on average, $107 \mathrm{ng} \mathrm{g}^{-1}$ during this experiment, whereas previous data reached values in the range $200-300 \mathrm{ng} \mathrm{g}^{-1}$ [17], with the difference being more dependent on coal than petroleum coke. The daily evolution showed a clear decreasing trend in coal, petroleum coke and fuel mixture, confirming that the sampling timing was appropriate.

Fly ash had very low $\mathrm{Hg}$ contents $\left(2 \mathrm{ng} \mathrm{g}^{-1}\right.$ on average), consistently with previous references $(0.3-$ $4.8 \mathrm{ng} \mathrm{g}^{-1}$ ) [17] and values $<10 \mathrm{ng} \mathrm{g}^{-1}$ for this plant [21]. For the sake of comparison, this value reached $1,300 \mathrm{ng} \mathrm{g}^{-1}$ in the nearest pulverized coal combustion (PCC) facility [21]. Slags had different grainsizes, with fine slags being more enriched ( $17 \mathrm{ng} \mathrm{g}^{-1}$ on average) than coarse slags ( $3 \mathrm{ng} \mathrm{g}^{-1}$ on average). Previous data showed lower values (1.2-2.3 $\mathrm{ng} \mathrm{g}^{-1}$ ) and this can probably be explained as due to the coarse slags category more than to the fine slags typology considered in this study. Sulphur had the highest $\mathrm{Hg}$ contents in solid slags or by-products, with an average value of $325 \mathrm{ng} \mathrm{g}^{-1}$ and a daily maximum of $469 \mathrm{ng} \mathrm{g}^{-1}$ on the first sampling day. Previous data on this aspect were not available, but these values are particularly important if sulphur is to be sold as a by-product and not treated as a waste. The capacity of sulphur to retain gaseous $\mathrm{Hg}$ has to be related to the proportions of $\mathrm{Hg}, \mathrm{S}$ and $\mathrm{Cl}$ in the raw materials [22]. Daily evolution trends were not significantly different for these solid waste and byproduct streams, except for sulphur, which showed a decreasing trend that mirrored the raw materials trend.

\subsection{Liquid Streams}

The presence of $\mathrm{Hg}$ in liquid streams varied from below the detection limit in the saturator to $745 \mathrm{ng} \mathrm{L}^{-1}$ in the slags system and up to $2,000 \mathrm{ng} \mathrm{L}^{-1}$ in the Venturi scrubber on average (Tab. 1). The variability was higher in the slags system ( $654 \mathrm{ng} \mathrm{L}^{-1}$ of standard deviation) than in the Venturi scrubber, while the evolution of $\mathrm{Hg}$ between sampling days did not show a common pattern, with a decreasing evolution in the Venturi scrubber and, surprisingly, an increasing trend in the slags system. Although the trend in the Venturi scrubber can be considered as negligible, given the low variations between days, the trend in the slags system must be evaluated along with trends in other streams of the facility in an effort to understand the reason for this opposite trend, and to rule out or confirm if the timing of the sampling was appropriate.

Table 1: Concentrations of $\mathrm{Hg}$ in solid and liquid samples. BDL: below detection limit

\begin{tabular}{lllll}
\hline & Day 1 & Day 2 & Day 3 & Average \\
\hline Solid streams (in $\mathrm{ng} \mathrm{g}^{-1}$ ) & & & & \\
Bituminous coal & 446 & 361 & 240 & 349 \\
Petroleum coke & 91 & 40 & 36 & 56 \\
Fuel mixture & 119 & 95 & 108 & 107 \\
Fly ash & 2 & 3 & 1 & 2 \\
Fine slags & 17 & 17 & 18 & 17 \\
Coarse slags & 3 & 4 & 1 & 3 \\
Sulphur & 469 & 370 & 137 & 325 \\
Liquid streams (in $\mathrm{ng} \mathrm{L}^{-1}$ ) & & & & 745 \\
Slags system & 283 & 459 & 1,494 & 2,075 \\
Venturi scrubber & 2,417 & 1,993 & 1,815 & \\
Saturator & BDL & BDL & BDL & \\
MDEA (in ng L $^{-1}$ ) & & & & 7.2 \\
\hline
\end{tabular}


The concentrations of $\mathrm{Hg}$ in $\mathrm{N}$-methyldiethanolamine (MDEA) were very low, with an average value of $7.2 \mathrm{ng} \mathrm{L}^{-1}$. It should be noted that MDEA is a reagent and not a component of the solid or liquid streams within the system that is consumed in the process. It is not possible to relate these $\mathrm{Hg}$ contents with the days selected for this study, since this reagent is always present in the process and is only replenished when necessary. However, we do not consider this as a limitation since, if this reagent acted as a sink for mercury, its $\mathrm{Hg}$ contents should have been much higher than the obtained results.

\subsection{Mass Balance}

In order to evaluate the mass balance, the $\mathrm{Hg}$ concentrations in the main material streams of the facility were considered together with the total flows used in the IGCC per hour of process. Since the sampling lasted for three days, the total daily amounts of each element analysed were calculated (Tab. 2) and, in this way, the total daily amount of $\mathrm{Hg}$ circulating through the facility in each currents and accumulating in the samples was obtained (Tab. 3).

Table 2: Average flows for each stream considered in the 24-hour sampling period

\begin{tabular}{llll}
\hline Dates & Day 1 & Day 2 & Day 3 \\
\hline Solid streams (in tons per day) & & & \\
Bituminous coal & 790.7 & 715.8 & 850.4 \\
Petroleum coke & 1344.3 & 1203.5 & 1250.2 \\
Fuel mixture & 1985.7 & 1786.4 & 1938.9 \\
Fly ash & 54.5 & 52.1 & 59.9 \\
Fine slags & 18.0 & 18.0 & 18.0 \\
Coarse slags & 378.7 & 310.9 & 392.7 \\
Sulphur & 86.6 & 72.4 & 55.0 \\
Liquid streams $\left(\right.$ in $\left.\mathrm{m}^{3} \mathrm{~h}^{-1}\right)$ & & & \\
Saturator & 0 & 0 & 0 \\
Venturi scrubber & 67,680 & 65,040 & 73,680 \\
Slags system & 48,000 & 112,560 & 48,000 \\
\hline
\end{tabular}

The detected trends may be useful to understand the trends in $\mathrm{Hg}$ evolution. In this sense, the results in Tab. 2 show a higher consumption of raw materials on Day 3 and this coincided with a higher production of wastes, including fly ashes and coarse and fine slags. In contrast, sulphur had a maximum value on Day 1 and a minimum on Day 3, thus providing evidence of a gap in production rhythms between wastes and byproducts. In the case of liquid streams, the saturator was considered to have a zero flow since it did not produce a constant residue stream, but rather accumulated with a not measurable flow at the scale of $\mathrm{m}^{3} \mathrm{~h}^{-1}$. The trend for the Venturi scrubber followed the main trend for wastes, with a maximum on the last sampling day, while the slags system followed a different trend that did not coincide with the trend for sulphur, with a maximum at Day 2.

The results showed that $\mathrm{Hg}$ entering the system (Tab. 3) during the sampling period was in the range 170-236 $\mathrm{g} \mathrm{day}^{-1}$, while the $\mathrm{Hg}$ present in the solid and liquid streams was in the range 8-42 $\mathrm{g} \mathrm{day}^{-1}$. It is necessary to highlight the great difference in scale between the inputs and the outputs through the $\mathrm{Hg}$ residues in the system, the $\mathrm{Hg}$ that enters the system daily reached figures of hundreds, while the outputs 
reached only values of units, with the notable exception of sulfur that reached values of tens. In addition, discontinuities were detected in the $\mathrm{Hg}$ entry and exit rates for the system, suggesting inertia in some sampled currents that could be distorting the results in daily terms. Some of the flows provided in Tab. 2 must be imprecise, mainly due to the difficulties in correctly estimating these flows in a system not designed to offer this type of information in the short term (i.e., on a daily basis). Despite this drawback, a pattern can be detected if we focus our attention on the order of streams in terms of Hg content on each sampling day: sulphur $>$ coarse slags $>$ fine slags $>$ Venturi scrubber $>$ fly ash $>$ slags system $>$ saturator.

Table 3: Mass balance of the studied samples, with the total amount of $\mathrm{Hg}$ by streams expressed in $\mathrm{g}$

\begin{tabular}{|c|c|c|c|c|}
\hline & Day 1 & Day 2 & Day 3 & Average \\
\hline Fuel mixture (g) & 236.30 & 169.71 & 209.40 & 205.14 \\
\hline Fly ash $(g)$ & 0.11 & 0.16 & 0.06 & 0.11 \\
\hline Coarse slags (g) & 1.14 & 1.24 & 0.39 & 0.92 \\
\hline Fine slags (g) & 0.31 & 0.31 & 0.32 & 0.31 \\
\hline Sulphur (g) & 40.65 & 26.80 & 7.54 & 25.00 \\
\hline Saturator $(\mathrm{g})$ & 0.00 & 0.00 & 0.00 & 0.00 \\
\hline Venturi scrubber (g) & 0.16 & 0.13 & 0.13 & 0.14 \\
\hline Slags system (g) & 0.01 & 0.03 & 0.01 & 0.02 \\
\hline Input $(\mathrm{g})$ & 236.30 & 169.71 & 209.40 & 205.14 \\
\hline Output (g) & 42.40 & 28.68 & 8.46 & 26.51 \\
\hline Balance $\left(\mathrm{g} \mathrm{d}^{-1}\right)$ & 193.90 & 141.03 & 200.95 & 178.63 \\
\hline Balance (\%) & 82.06 & 83.10 & 95.96 & 87.04 \\
\hline
\end{tabular}

The percentage of $\mathrm{Hg}$ removed by the solid and liquid streams was in the range $4 \%-18 \%$ (Figs. $2 \mathrm{a}$ and $2 \mathrm{~b}$ ). Most of the $\mathrm{Hg}$ removed was found in the sulphur unit recovery (12\% on average), in accordance with previous studies on other IGCC power plants [6], while liquid streams removed only $0.08 \%$ on average. Daily trends clearly showed differences in the operating rhythms of the system, with a slight or zero increase between days one and two, and a clear decrease on day three. These differences explain the inconsistencies between the evolution trends of $\mathrm{Hg}$ in solid and liquid streams, especially in the slags system.
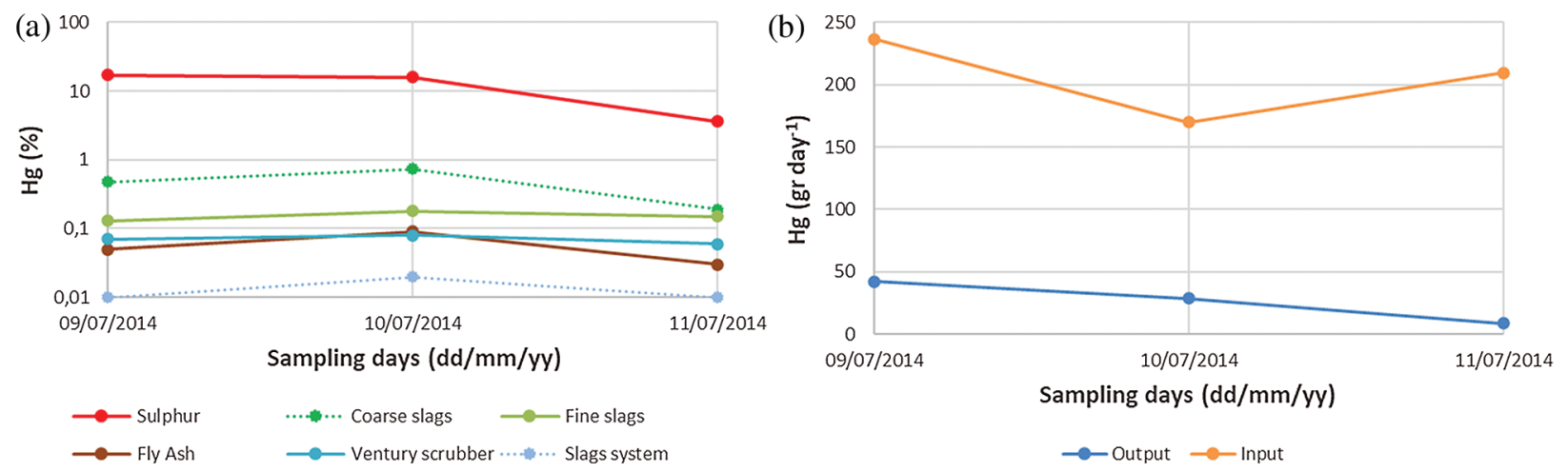

Figure 2: Mass balance of the studied samples, indicating the total amount of $\mathrm{Hg}$ by streams expressed in \% (a), and the relationship between input and output expressed in $\mathrm{g} \mathrm{day}^{-1}$ (b) 


\subsection{Mercury Thermal Speciation}

The results of the $\mathrm{Hg}$ pyrolytic speciation analysis in the sulphur samples provided desorption temperatures consistent with those detected in $\mathrm{Hg}$ bound to humic acids in soil samples (internal standard), as can be seen in Fig. 3. This speciation technique has a limitation in terms of the detection limit and this made it impossible to obtain the same data from the slag samples (fine and coarse) or from the fly ash, having very low $\mathrm{Hg}$ contents. It was also not possible to obtain data on the raw materials: both coal and petroleum coke are combustible and in the analytical equipment ambient air was used as the carrier gas, so it was impossible to avoid combustion of the coal and coke during the analysis.

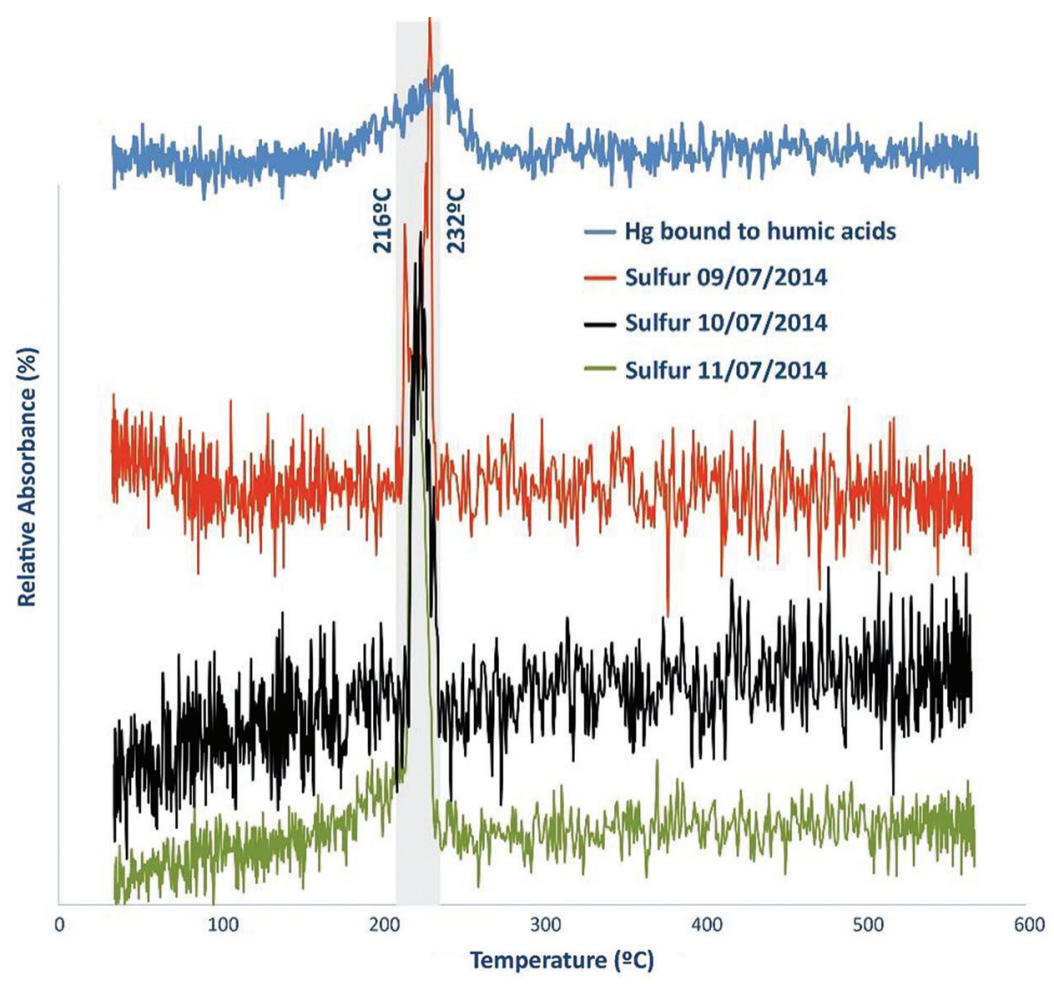

Figure 3: Thermal desorption profiles for $\mathrm{Hg}$ present in sulphur samples

The data provided by this speciation technique could not unequivocally identify the compound in question, as discussed by other authors [23], because there were numerous compounds that desorb $\mathrm{Hg}$ at very similar temperatures and because these temperatures were specific to each set of analytical equipment and to the laboratory conditions. The desorption temperature range shown by the sulphur samples was similar to the range of the internal standard ( $\mathrm{Hg}$ bound to humic acids) and consistent with the desorption range found in reference [23] for this compound. The compounds that desorb $\mathrm{Hg}$ at similar temperatures include $\mathrm{HgBr}_{2}, \mathrm{HgI}_{2}, \mathrm{Hg}_{2} \mathrm{Cl}_{2}, \mathrm{HgCl},\left(\mathrm{CH}_{2} \mathrm{COO}\right)_{2} \mathrm{Hg}, \mathrm{Hg}\left(\mathrm{NO}_{3}\right)_{2}$ and $\mathrm{MeHg}$, but their desorption temperatures are usually below $200^{\circ} \mathrm{C}$ and they can therefore be ruled out as candidates.

\subsection{Gaseous $\mathrm{Hg}$ in the Ojailén Valley}

The results obtained in our survey to quantify the presence of GEM in the ELCOGAS IGCC plant and its surroundings showed low or very low $\mathrm{Hg}$ values in the air (less than $8 \mathrm{ng} \mathrm{m}^{-3}$ ). However, the distribution suggested IGCC power plant as the maximum source of emission in the Ojailén valley, despite the existence of a refinery, another coal combustion power plant, and an open-pit coal mine, since anomalous 
values greater than $7 \mathrm{ng} \mathrm{m}^{-3}$ were only measured at the IGCC facility and only the coal mine area gave slightly lower values $\left(<6 \mathrm{ng} \mathrm{m}^{-3}\right)$. It can be seen in Fig. 4a that the values were higher close to the laboratories, but not in the coal storage area located to the south of the facility. On the other hand, the dispersion of the anomalous values $\left(>6 \mathrm{ng} \mathrm{m}^{-3}\right)$ around the installation reached at least $1.5 \mathrm{~km}$ (Fig. $4 \mathrm{~b}$ ). The emissions from chimneys with high temperatures did possibly not produce high values in the vicinity, due to the pollutant lifting capacity of the plume, which will reach variable heights depending mainly on atmospheric stability and wind speed, according to dispersion curves described by PasquillGifford-Turner [24]. This was evidenced by some authors [25] that monitored the GEM for a whole year in the neighbouring town of Puertollano (10 km away) and did not register values higher than $7.32 \mathrm{ng} \mathrm{m}^{-3}$.

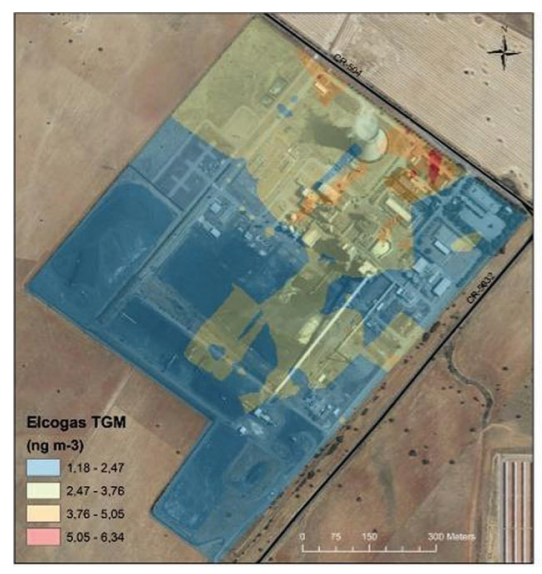

(a)

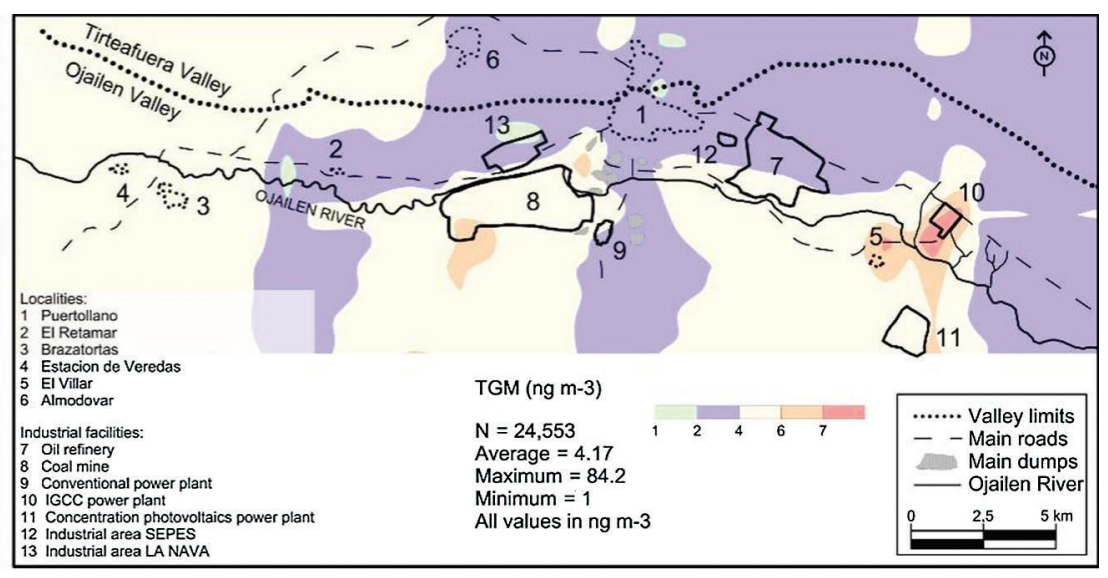

(b)

Figure 4: Distribution of gaseous elemental $\mathrm{Hg}$ at the ELCOGAS facility (a) and in the Ojailén valley (b). Map of the Ojailén valley was adapted from [25]

\subsection{Mercury Mass Balance Uncertainties and Their Possible Causes}

In this work, the total daily amounts of $\mathrm{Hg}$ in each of the analysed streams of an IGCC power plant were estimated. The results show that there were no Hg losses from the fuel mixture production process and that most $\mathrm{Hg}$ was removed from the system by the solid streams (26.34 $\mathrm{g}$ on average), with sulphur constituting the main route for the elimination of $\mathrm{Hg}$ ( $25 \mathrm{~g}$ on average) through solid waste. The liquid streams barely removed $0.16 \mathrm{~g}$ on average but it was difficult to estimate how much $\mathrm{Hg}$ per day the water withdraws from the saturator, having this stream a flow zero and acting therefore as a sink, which cannot be included in the calculation of a daily balance of $\mathrm{Hg}$ passing through the system. The $\mathrm{Hg}$ content in this liquid phase was not higher than in the Venturi scrubber and therefore the contribution of this liquid phase to the total mass balance was not important.

The total balance showed an average of $205.14 \mathrm{~g}$ of $\mathrm{Hg}$ entering into the system during the three days of sampling and $26.51 \mathrm{~g}$ of $\mathrm{Hg}$ leaving via the solid and liquid sampled streams. On this basis, the average daily amount of $\mathrm{Hg}$ that was not eliminated through the analysed streams was $178.63 \mathrm{~g}$, representing $87.04 \%$ of the total $\mathrm{Hg}$ entering with the fuel mixture.

An assessment of the total amounts of $\mathrm{Hg}$ in each of the streams determined with respect to the fuel mixture showed a very significant daily variability, especially in terms of the solid streams. This variability may be due to several factors but mainly to the heterogeneity of the solid currents. In order to delimit the different rhythms of each of the currents analysed in this study, a Pearson correlation analysis 
was carried out (within the limitations of the available data). In a daily analysis, the fuel mixture only showed significant correlation with the liquid samples from the Venturi scrubber, so the lack of accuracy in the period used for the calculation of the total amounts of $\mathrm{Hg}$ was the main factor distorting the mass balance. However, the solid waste streams showed significant correlations with each other and this fact would diminish the importance of the previous statement and would confirm that daily sampling was appropriate to carry out a mass balance. A multivariate analysis showed that there were three clearly differentiated groups in terms of $\mathrm{Hg}$ contents (Fig. 5): fly ash, coarse slag and slag system liquid (group 1); sulphur, coal, Venturi scrubber and coke (group 2); and fine slag without a relationship with the other streams. It is highly significant that the fuel raw materials (coal and petroleum coke) appeared related to each other in group 2, and also to the samples from the Venturi scrubber-especially to the sulphur. The reasons for this close relationship could be that the flow rates of materials in these four cases was particularly well established and that there were therefore differences in the flows of other used currents, such as the slag system, with coarse and fine slags and fly ash. In any case, in general terms the Hg entering the system through raw materials seemed to be related with that leaving the system in the cleaning units of the syngas, mainly in the Venturi scrubbers and sulphur recovery units. Although it was not possible to confirm that $\mathrm{Hg}$ was retained in these units due to a lack of data to complete the mass balance, it is possible to assume that these are the units retaining $\mathrm{Hg}$ in appreciable proportions, i.e., at the same rate as $\mathrm{Hg}$ entered into the system.

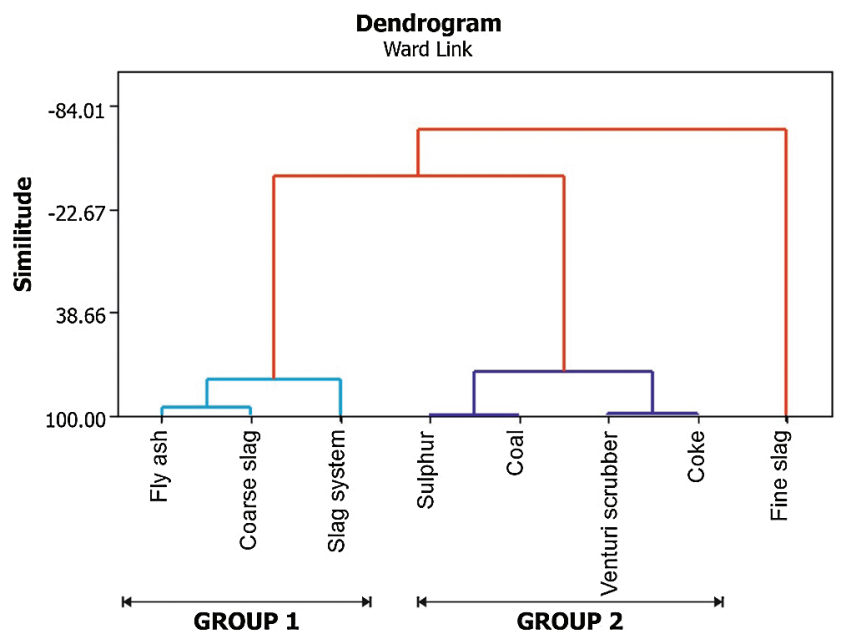

Figure 5: Dendrogram for the main considered streams

Another important issue is to answer key questions regarding $\mathrm{Hg}$ losses: which are the conditions that favour $\mathrm{Hg}$ retention in sulphur? Moreover, if the $\mathrm{Hg}$ retained in the sulphur represents only $12.2 \%$ on average of the $\mathrm{Hg}$ that enters in the system, which are the conditions that allow $87 \%$ of the $\mathrm{Hg}$ not to be trapped by sulphur? Where is the remaining $\mathrm{Hg}$ ? It seems clear that in the desulphurization system of the ELCOGAS plant, $\mathrm{H}_{2} \mathrm{~S}$ is oxidized to elemental sulphur in the presence of $\mathrm{O}_{2}$ and $\mathrm{H}_{2} \mathrm{O}$ at temperatures that can be considered as intermediate between hot gas and cold gas [26]. Under these conditions, GEM in the gas phase that is still present in the syngas will react with the elemental sulphur in the S-condenser forming metacinnabar (HgS). Under such conditions of sulphur excess, all GEM contained in the syngas should react and be fixed as metacinnabar. However, the results of a speciation analysis contradict this statement, as $\mathrm{Hg}$ was found in sulphur as a compound with similar desorption temperature to $\mathrm{Hg}$ bound to humic 
acids in soils and slightly higher than the desorption temperature of organic $\mathrm{Hg}$ compounds like methylmercury [27]. The compound containing $\mathrm{Hg}$ could not be properly identified, but it can be stated that it had desorption temperatures similar to organic Hg compounds, suggesting that some organic compound present in the analysed system could be capturing GEM from the syngas. Another possibility is that in the temperature drop over which the desulphurization plant works, the high-temperature polymorph of cinnabar, i.e., hypercinnabar, was formed. This polymorph of mercuric sulphide would begin to form at temperatures above $480^{\circ} \mathrm{C}$ [28], i.e., compatible with the cooling process of the syngas from the gasification unit $\left(>1500^{\circ} \mathrm{C}\right)$ to the sulphur separation unit $\left(30^{\circ} \mathrm{C}\right)$. Whether $\mathrm{Hg}$ was fixed in the solid sulphur $(12.2 \%)$ or it was removed from the syngas $(87 \%)$, the main candidate to fix $\mathrm{Hg}$ was the main reagent used in the Claus system, namely $N$-methyldiethanolamine (MDEA) [9]. The possibility that $\mathrm{Hg}$ was underestimated in other solid wastes (mainly slags and fly ashes) must also be considered due to the heterogeneity in solid streams, which made it difficult to be precise with the mass balance, as mentioned above. However, $87 \%$ of $\mathrm{Hg}$ losses seemed a percentage too large to be due to an error. Slags from the ELCOGAS facility uptake more Hg than those of other similar IGCC power plants [29] and it is therefore possible that some specific aspect of the ELCOGAS system is causing anomalous $\mathrm{Hg}$ retention in slags, especially in fine slags. These possibilities are reasonable but not verifiable with the available data. Another explanation is the existence of a fixation process in MDEA solution, a process demonstrated in similar units in other power plants [30,31] and consistent with $\mathrm{Hg}$ speciation data in sulphur. Such desulphurization units using MDEA as the reagent are usually located downstream from a mercury recovery unit with commercial activated carbon beds and problems with the Hg enrichment are not observed. However, the ELCOGAS plant have not a mercury recovery unit upstream and most of the GEM from the bituminous coal remains in the syngas. The solubility of $\mathrm{Hg}$ in MDEA is dependent on the temperature and pressure [32] and the operation range of the ELCOGAS facility in the 'goldilocks zone' for mercury retention in the reagent. Unfortunately, the $\mathrm{Hg}$ concentrations present in the MDEA were negligible ( $7.2 \mathrm{ng} \mathrm{L}^{-1}$ on average) and this rule out the possibility outlined above.

Finally, it is necessary to mention the possibility that $\mathrm{Hg}$ continued to be part of the syngas, burned in the combustion process to produce electricity and then emitted via the chimney. Unfortunately, it was not possible to obtain a syngas sample to determine the GEM concentration due to technical difficulties. In any case, the low efficiency of sulphur in retaining $\mathrm{Hg}$ suggests that the proportion of GEM that can reach the combustion unit in the syngas may be significant. This point has not been proven either, since the GEM values measured in the vicinity do not justify or deny this possibility.

\section{Conclusions}

- The mass balance of the solid and liquid streams analysed in this study indicates that an average of $12.9 \%$ of the $\mathrm{Hg}$ that enters the IGCC power plant is eliminated with solid waste and only $0.08 \%$ with liquid waste. There is still an average of $87.12 \%$ of $\mathrm{Hg}$ that is not accounted for in the mass balance and that could remain in the system and/or be eliminated in the streams that were not unfortunately analysed.

- In the daily mass balance, marked variations are observed without a significant correlation between the $\mathrm{Hg}$ entering the system and that analysed in the solid and liquid outgoing streams. This discrepancy may be due to a phenomenon of asynchrony in the sampling timing or because there is remaining $\mathrm{Hg}$ in the system.

-Although it is not possible to explain the final fate of the $\mathrm{Hg}$ lost in the system based on our results, the data suggest that a sulphur by-product may be mainly responsible for the elimination of $\mathrm{Hg}$ from the syngas, and that a major proportion of $\mathrm{Hg}$ could be emitted through chimney after syngas combustion process. 
Acknowledgement: The authors would like to thank the staff of the ELCOGAS Company, especially Francisco García-Peña, Pilar Coca and Alejandro Muñoz-Mozos, for their collaboration in taking samples and the information provided on the IGCC.

Funding Statement: The present study was funded by Spanish Ministry of Economy and Competitiveness (Project CTM2012-33918) and ICEX España Exportación e Inversiones (Project 2014/03076).

Conflicts of Interest: The authors declare that they have no conflicts of interest to report regarding the present study.

\section{References}

1. Pirrone, N., Cinnirella, S., Feng, X., Finkelman, R. B., Friedli, H. R. et al. (2010). Global mercury emissions to the atmosphere from anthropogenic and natural sources. Atmospheric Chemistry and Physics, 10(13), 5951-5964. DOI 10.5194/acp-10-5951-2010.

2. Environmental Protection Agency (2011). Electric Generating Utility Mercury Speciation Profiles for the Clean Air Mercury Rule. In: EPA-454/R-11-010, Research Triangle Park, NC, USA, 2011; Atluri, S. N., Zhu, T. (1998). A new meshless local petrov-galerkin (MLPG) approach in computational mechanics. Computational Mechanics, North Carolina: U.S. Environmental Protection Agency, vol. 22, pp. 117-127.

3. Zhang, Y., Jaeglé, L., van Donkelaar, A., Martin, R. V., Holmes, C. D. et al. (2012). Nested-grid simulation of mercury over North America. Atmospheric Chemistry and Physics, 12, 6095-6111. DOI 10.5194/acp12-60952012.

4. Kos, G., Ryzhkov, A., Dastoor, A., Narayan, J., Steffen, A. et al. (2013). Evaluation of discrepancy between measured and modelled oxidized mercury species. Atmospheric Chemistry and Physics, 13, 4839-4863, DOI 10.5194/acp-13-4839-2013.

5. Mayer, J., Hopf, S., van Dijen, F., Baldini, A. (2014). Measurement of low mercury concentrations in flue gases of combustion plants. Gefahrstoffe Reinhaltung Der Luft, 74(4), 157-163.

6. Wang, T. (2017). An overview of IGCC systems. Integrated Gasification Combined Cycle (IGCC) Technologies, 2017, 1-80. DOI 10.1016/B978-0-08-100167-7.00001-9.

7. Holleman, A. F., Wiber, E., Wiberg, N., (2001). Inorganic chemistry, San Diego: Academic Press 810.

8. Griffiths, J. (2003). Reactions: Mercury removal. Chemical Engineer, (742), 55.

9. Casero, P., García-Peña, F., Coca, P. (2013). Elcogas pre-combustion carbon capture pilot, real experience of commercial technology. Paper Presented at the Energy Procedia, 37, 6374-6382. DOI 10.1016/j. egypro.2013.06.567.

10. Cabezón, P. C., Llano, P. C., García-Peña, F., Hervás, N. (2013). $\mathrm{CO}_{2}$ emissions reduction technologies in IGCC: ELCOGAS's experiences in the field. Greenhouse Gases: Science and Technology, 3(4), 253-265. DOI 10.1002/ ghg.1351.

11. UNEP. Minamata Convention on Mercury. Text and Annexes. (2019). https://www.mercuryconvention.org/ Portals/11/documents/Booklets/COP3-version/Minamata-Convention-booklet-Sep2019-EN.pdf.

12. ElCOGAS (2010). IGCC Puertollano. A Clean Coal Gasification Power Plant, José Damián Bogas Gálvez y Manuel Treviño Coca (Ed.). Madrid.

13. Sholupov, S., Pogarev, S., Ryzhov, V., Mashyanov, N., Stroganov, A. (2004). Zeeman atomic absorption spectrometer RA-915+ for direct determination of mercury in air and complex matrix samples. Fuel Processing Technology, 85(6-7), 473-485. DOI 10.1016/j.fuproc.2003.11.003.

14. Biester, H., Scholz, C. (1997). Determination of mercury binding forms in contaminated soils: Mercury pyrolysis versus sequential extractions. Environmental Science and Technology, 31(1), 233-239. DOI 10.1021/es960369h.

15. Environmental Protection Agency (2005). Method 245.7, Mercury in Water by Cold Vapor Atomic Fluorescence Spectrometry. Engineering and Analysis Division, (4303), Washington DC: U.S. Environmental Protection Agency. 
16. Esbrí, J. M., Higueras, P., Martínez-Coronado, A., Naharro, R. (2020). 4D dispersion of total gaseous mercury derived from a mining source: Identification of criteria to assess risks related with high concentrations of atmospheric mercury. Atmospheric Chemistry and Physics, 20, 12995-13010. DOI 10.5194/acp-20-12995-2020.

17. Font, O., Querol, X., Izquierdo, M., Alvarez, E., Moreno, N. et al. (2010). Partitioning of elements in a entrained flow IGCC plant: Influence of selected operational conditions. Fuel, 89(11), 3250-3261. DOI 10.1016/j. fuel.2010.03.044.

18. Alastuey, A., Jiménez, A., Plana, F., Querol, X., Suárez-Ruiz, I. (2001). Geochemistry, mineralogy, and technological properties of the main stephain (carboniferous) coal seams from the puertollano basin, Spain. International Journal of Coal Geology, 45(4), 247-265. DOI 10.1016/S0166-5162(00)00036-7.

19. Lang, D., Gardner, M., Holmes, J. (2012). Mercury arising from oil and gas Production in the United Kingdom and UK continental shelf; Integrating Knowledge to Inform Mercury Policy, University of Oxford.

20. Ruszkowski, M. F., Radoševiæ, M., Podolski, Š, Gorup, R., Mariæ, Z. (2010). Croatian crude oils 30 years ago and today (analysis and distillation). Nafta, 61(9), 399-404.

21. Font, O., Moreno, N., Díez, S., Querol, X., López-Soler, A. et al. (2009). Differential behaviour of combustion and gasification fly ash from puertollano power plants (Spain) for the synthesis of zeolites and silica extraction. Journal of Hazardous Materials, 166(1), 94-102. DOI 10.1016/j.jhazmat.2008.10.120.

22. Morris, E. A., Morita, K., Jia, C. Q. (2010). Understanding the effects of sulfur on mercury capture from coal-fired utility flue gases. Journal of Sulfur Chemistry, 31(5), 457-475. DOI 10.1080/17415993.2010.493199.

23. Saniewska, D., Bełdowska, M. (2017). Mercury fractionation in soil and sediment samples using thermodesorption method. Talanta, 168, 152-161. DOI 10.1016/j.talanta.2017.03.026.

24. Martínez-Coronado, A., Esbrí, J. M., Higueras, P. (2016). Time variations of gaseous and reactive mercury in the industrial area of puertollano (south-central Spain). temporal cycles with marked variations. Atmospheric Environment, 134, 198-207. DOI 10.1016/j.atmosenv.2016.03.049.

25. Venkatram, A. (1996). An examination of the pasquill-gifford-turner dispersion scheme. Atmospheric Environment, 30(8), 1283-1290. DOI 10.1016/1352-2310(95)00367-3.

26. Srinivas, G., Gebhard, S., Spalding, W., Vidaurri, J. (2009). Multicontaminant warm gas cleanup. Paper Presented at the 26th Annual International Pittsburgh Coal Conference 2009, PCC, Pittsburgh, 2009(1), 844-857.

27. Rumayor, M., Lopez-Anton, M. A., Díaz-Somoano, M., Maroto-Valer, M. M., Richard, J. et al. (2016). A comparison of devices using thermal desorption for mercury speciation in solids. Talanta, 150, 272-277. DOI 10.1016/j.talanta.2015.12.058.

28. Potter, R. W., Barnes, H. L. (1978). Phase relations in the binary Hg-s. American Mineralogist, 63, 1143-1152. https://pubs.geoscienceworld.org/msa/ammin/article-abstract/63/11-12/1143/40822/Phase-relations-in-the-binaryHg-S?redirectedFrom=PDF

29. Duchesne, M. A., Hughes, R. W. (2014). Partitioning of inorganic elements in pilot-scale and demonstration-scale entrained-flow gasifiers. Fuel, 127, 219-227. DOI 10.1016/j.fuel.2013.08.051.

30. Zhang, L. X., Jiang, H., Zhang, L. (2018). Study on mercury distribution in different natural gas treatment plants. Xiandai Huagong/Modern Chemical Industry, 38(1), 201-205. DOI 10.16606/j.cnki.issn0253-4320.2018.01.048.

31. Zhang, S., Jiang, H. (2017). Mercury distribution in natural gas decarburization plant. Xiandai Huagong/Modern Chemical Industry, 37(7), 192-195. DOI 10.16606/j.cnki.issn0253-4320.2017.07.046.

32. Yan, Q. T., Zhao, Y. L., Li, J., Duan, Y. F., Wang, S. Y. et al. (2018). Determination of the mercury solubility in several natural Gas processing fluids. Proceedings of the International Workshop on Environmental Management, Science and Engineering, pp. 201-206, Xiamen, China. 